\title{
Backstepping Control with Integral Action of PMSM Integrated According to the MRAS Observer
}

\author{
A. Larbaoui ${ }^{1}$, B. Belabbes ${ }^{1}$, A. Meroufel ${ }^{1}$, A.Tahour $^{1}$, and D. Bouguenna ${ }^{2, *}$. \\ 1(Intelligent Control Electronic Power System Laboratory (I.C.E.P.S), University of Ddjilali Liabes, BP 98, Sidi \\ Bel Abbes, Algeria). \\ 2(Department of LMD Matter Sciences (SM), Faculty of Sciences and Technology, University of Mascara, Road \\ of Mamounia, 29000 Mascara, Algeria).
}

\begin{abstract}
The work developed in this article, has aims to control design law is based on Backstepping method to ensure the servo-control of the permanent magnet synchronous motors (PMSM). The slow convergence of adaptation can result, in some cases; irreversible instabilization loop, especially in the presence of nonlinearity and/or couplings. Hence, the Backstepping method coupled with introduction of integral actions is an alternative choice. Moreover, the Backstepping theory is a recursive design methodology that makes use of the Lyapunov stability theory. Strong properties of overall and asymptotic stability can be achieved. The second part of this work is a direct application of the control proposed to associate an observer, is the Model Reference Adaptive System (MRAS) to observe the position and the rotor speed of the MRAS. Furthermore, the simulation under the Matlab/Simulink software allows highlighting the performance of the control strategy adopted. Keywords: Backstepping control, Lyapunov theorem, Integral action, Permanent Magnet Synchronous Motor (PMSM), Model Reference Adaptive System (MRAS), observer.
\end{abstract}

\section{Introduction}

During several years, the industry has been gradually replacing DC motors in a wide range of drive applications such as machine tools and industrial robots offer the main advantage to be easily controllable through decoupling flux and torque control. However, the presence of the collector and brushes have been always a great disadvantage of motor among other limiting increasingly use.

Address this limitation; PMSM is more attractive because they meet all the requirements. Furthermore, the coupling existing between the flux and torque makes the PMSM hardly controllable. With nonlinear control it is possible to obtain variable speed AC as well as drives speed of DC motors [1]. When the part controlled is submitted for perturbations and for changing the system parameters, a self adaptive solution should be considered by adjustment of controller parameters of regulators, which allow keeping the performances fixed advance in presence of perturbations and of change in the system parameters. This solution present has a disadvantage of requiring an implementation often complex. Thus, it is possible to consider a more simple solution, using a special nonlinear control system class called, Backstepping control [1, 3, 4].

The technical proposed in our work is to control design law for the PMSM to achieve high statics and dynamics performance. This technique is based on the Backstepping technique which establishes relations successive causal iteratively to build a systematic and robust control law asymptotically stable according to the Lyapunov theory of stability [5]. The influence of the change some parameters and of the perturbation of charge can be greatly reduced by the introduction of an integral action in each step, in order to ensure high accuracy speed control [6].

The paper is organized as follows: in Section II an overview of the description of PMSM mathematical model in $(d-q)$ reference coordinate system. In Section III the control design law is based on Backstepping control theory in integral action. Then, the Section IV will be devoted to the design of the control without speed sensor associated with MRAS observer for PMSM with salient poles. Section V presents some simulation results and we conclude the paper in the last Section of this paper.

\section{PMSM mathematical model}

Electric and dynamic behavior of electrical machines can't be studied if it is defined by a mathematical model. To obtain a simpler formulation and reduce the complexity of the machine model, the establishment of its mathematical model will be developed based on simplifying assumptions.

Knowing that:

- The machine is symmetrical,

- Operate in the unsaturated regime,

- The various losses are negligible, 
- The excitation is done by permanent magnets, such as the excitation flux is considered constant, $[1,3]$. Furthermore, the magnet is considered a winding without resistance or inductance or mutual, but as a flux source.

Using transformations Park, the PMSM mathematical model in rotating reference frame $(d-q)$, is defined by the following system of equations:

$$
\left\{\begin{array}{l}
\frac{d i_{d}}{d t}=-\frac{R_{s}}{L_{d}} i_{d}+\frac{L_{q}}{L_{d}} p \omega_{r} i_{q}+\frac{1}{L_{d}} v_{d} \\
\frac{d i_{q}}{d t}=-\frac{R_{s}}{L_{q}} i_{q}-\frac{L_{d}}{L_{q}} p \omega_{r} i_{d}-\frac{\psi_{f}}{L_{q}} p \omega_{r}+\frac{1}{L_{q}} v_{q} \\
\frac{d \omega_{r}}{d t}=\frac{3 p}{2 j}\left(\psi_{f} i_{q}+\left(L_{d}-L_{q}\right) i_{d} i_{q}\right)-\frac{1}{j} T_{L}-\frac{B_{m}}{j} \omega_{r} \\
\frac{d \theta}{d t}=p \omega_{r}
\end{array}\right.
$$

with:

$R_{S} \quad$ stator resistance,

$L_{d}, L_{q}$ d and q-axis inductances,

$\psi_{f} \quad$ permanent-magnet flux linkage,

$i_{d}, i_{q}$ stator currents,

$v_{d}, v_{q}$ stator voltages,

$\omega_{r} \quad$ rotor speed in angular frequency,

$\theta \quad$ rotor angular position,

$j$ moment of inertia of the motor and load,

$B_{m} \quad$ friction coefficient of the motor,

$p \quad$ number of pole pairs,

$T_{L} \quad$ load torque.

\section{Backstepping control with integral action for PMSM}

This part of the article studies the strategy of speed control by the Backstepping technique. This technique of non-linear control has been recently developed; it can be effectively used for linearizing a non-linear system in the presence of uncertainties [6-9].

The control technique is a nonlinear Backstepping control having properties of strength. The pursuit of speed takes place with a high yield by the control voltage $v_{q}$ as long as the current $i_{d}$ is kept equal to zero.

The basic idea of the type Backstepping control is to make curly equivalent subsystems of order 1 systems in cascade stable within the meaning of Lyapunov, which gives them the qualities of robustness and a global asymptotic stability [1], [5]. In other words, this is a multi-step method. At each step of the process, a virtual control is also generated to ensure the convergence of system to its equilibrium state. This can be reached from Lyapunov functions to ensure step by step the stabilization of each synthesis step. The idea is to compute a control law to ensure the Lyapunov function that is positive definite and its derivative is always negative.

The calculation of Lyapunov function is performed in a recursive way. It is based on the previous system state. A new Control Lyapunov Function (CLF) is constructed by the increase of CLF of the previous step [8]. This procedure calculates allow us to ensure overall system stability. The improvement of the robustness of this technique by incorporation of introduction in terms integrations of the control design of PMSM thereafter.

\section{III.1. Speed loop}

To solve speed tracking problem, define the following speed tracking error as:

$$
\varepsilon_{\Omega}=\omega_{\text {rref }}-\omega_{r}+k_{\Omega}^{\prime} \int_{0}^{t}\left(\omega_{r r e f}-\omega_{r}\right) d t
$$

where $k_{\Omega}^{\prime} \int_{0}^{t}\left(\omega_{r \text { ref }}-\omega_{r}\right) d t$ : is an integral action term added to the control in Backstepping to ensure the convergence of the tracking error to zero in spite of the uncertainties of such piecewise constant at each step of the algorithm.

The virtual control input $i_{q \text { ref }}$ used to ensure the stability of the speed loop. The error dynamics of speed from Eq. (2) is given by: 


$$
\begin{aligned}
\dot{\varepsilon}_{\Omega}= & \dot{\omega}_{r \text { ref }}-\frac{p}{j}\left(L_{d}-L_{q}\right) i_{d} i_{q r e f}+\frac{B_{m}}{j} \omega_{r}-\frac{p}{j} \psi_{f} i_{q r e f}+\frac{1}{j} T_{L}+ \\
& k_{\Omega}^{\prime}\left(\omega_{\text {rref }}-\omega_{r}\right) .
\end{aligned}
$$

Consider the following Lyapunov candidate function: $V_{\Omega}=\frac{1}{2} \varepsilon_{\Omega}^{2}$ its derivative is given by the following equation:

$\dot{V}_{\Omega}=\varepsilon_{\Omega}\left\{\dot{\omega}_{r}-\frac{p}{j}\left(L_{d}-L_{q}\right) i_{d} i_{q r e f}+\frac{B_{m}}{j} \omega_{r}-\frac{p}{j} \psi_{f} i_{q r e f}+\frac{1}{j} T_{L} k_{\Omega}^{\prime}\left(\omega_{\text {r ref }}-\omega_{r}\right)\right\}$.

Following the Backstepping methodology, and in order to ensure the stability of speed tracking, the virtual control $i_{q \text { ref }}$ is given by the following equation:

$i_{q r e f}=\frac{j}{p \psi_{f}+p\left(L_{d}-L_{q}\right) i_{d}}\left[k_{\Omega} \varepsilon_{\Omega}+\dot{\omega}_{\text {rref }}+\frac{B_{m}}{j} \omega_{r}+k_{\Omega}^{\prime}\left(\omega_{\text {rref }}-\omega_{r}\right)+\frac{1}{j} T_{L}\right]$.

Then $\dot{V}_{\Omega}=-k_{\Omega} \varepsilon_{\Omega}^{2}$, with $k_{\Omega}>0$.

\section{III.2. Current loop $\boldsymbol{i}_{q}$}

Since the virtual input $i_{q \text { ref }}$ is designed to stabilize the dynamics Eq. (3), now to design the control input $v_{q}$ we define the tracking error in the current as follows:

$\varepsilon_{q}=i_{q r e f}-i_{q}+\varepsilon_{q}^{\prime}$,

where $\varepsilon_{q}^{\prime}=k_{q}^{\prime} \int_{0}^{t}\left(i_{q \text { ref }}-i_{q}\right) d t$ is an integral action. Consider the following Lyapunov candidate function:

$V_{q}=V_{\Omega}+\frac{1}{2} \varepsilon_{q}^{2}+\frac{1}{2} \varepsilon_{q}^{\prime 2}$

By taking the time derivative of $V_{q}$ is given by:

$\dot{V}_{q}=-k_{\Omega} \varepsilon_{\Omega}^{2}+\varepsilon_{q}\left\{\frac{d i_{q r e f}}{d t}-\frac{d i_{q}}{d t}+k_{q}^{\prime}\left(i_{q r e f}-i_{q}\right)\right\}+\varepsilon_{q}^{\prime} k_{q}^{\prime}\left(i_{q r e f}-i_{q}\right)$,

Replacing by: $\frac{d i_{q}}{d t}=-\frac{R_{s}}{L_{q}} i_{q}-\frac{L_{d}}{L_{q}} p \omega_{r} i_{d}-\frac{\psi_{f}}{L_{q}} p \omega_{r}+\frac{1}{L_{q}} v_{q}$, then Eq. (8) becomes:

$\dot{V}_{q}=-k_{\Omega} \varepsilon_{\Omega}^{2}+\varepsilon_{q}\left\{\frac{d i_{q r e f}}{d t}+\frac{R_{s}}{L_{q}} i_{q}-\frac{1}{L_{q}} v_{q}+p \frac{L_{d}}{L_{q}} \omega_{r} i_{d}+p \frac{1}{L_{q}} \psi_{f} \omega_{r}+k_{q}^{\prime}\left(i_{q r e f}-i_{q}\right)\right\}+$

$\varepsilon_{q}^{\prime} k_{q}^{\prime}\left(i_{q r e f}-i_{q}\right)$.

By choosing the control input $v_{q}$ as:

$v_{q}=L_{q}\left[k_{q} \varepsilon_{q}+2 \frac{p}{j} \psi_{f} \varepsilon_{\Omega}+p \frac{\psi_{f}}{L_{q}} \omega_{r}+\frac{R_{s}}{L_{q}} i_{q}+\frac{d i_{q r e f}}{d t}\right]$.

It is obtain that:

$\dot{V}_{q}=-k_{\Omega} \varepsilon_{\Omega}^{2}-k_{q} \varepsilon_{q}^{2}+\left\{\varepsilon_{q}+\varepsilon_{q}^{\prime}\right\} k_{q}^{\prime}\left(i_{q r e f}-i_{q}\right)$.

Replacing by: $i_{q \text { ref }}-i_{q}=\varepsilon_{q}+\varepsilon_{q}^{\prime}$, then Eq. (11) becomes:

$\dot{V}_{q}=-k_{\Omega} \varepsilon_{\Omega}^{2}-k_{q} \varepsilon_{q}^{2}+\left\{\varepsilon_{q}+\varepsilon_{q}^{\prime}\right\} k_{q}^{\prime}\left(i_{q \text { ref }}-i_{q}\right)$,

with $\dot{V}_{q} \leq-\bar{K}_{q} V_{q}$

where $\bar{K}_{q}=\min \left\{k_{\Omega} ;\left\{k_{q}+k_{q}^{\prime}\right\} ; k_{q}^{\prime}\right\}$. Then, under the control action $v_{q}$ the current $i_{q}$ tracks input $i_{q \text { ref }}$, and by choosing the virtual control input $i_{q \text { ref }}$ is calculated which the speed tracking its reference: $\left(\omega_{r} \rightarrow \omega_{r \text { ref }}\right)$.

\section{III.3. Current loop $i_{d}$}

To eliminate the reluctance torque, the current reference is fixed to zero, $i_{d \text { ref }}=0$, it meets another objective of our control that is elimination of the reluctance effect. We obtain a similar operation to that of a DC machine separately excited; let us define the following tracking error: $\varepsilon_{d}=i_{d r e f}-i_{d}+\varepsilon_{d}^{\prime}$, 
where: $\varepsilon_{d}^{\prime}=k_{d}^{\prime} \int_{0}^{t}\left(i_{d r e f}-i_{d}\right) d t$ is an integral action. Defining the following candidate Lyapunov function:

$V_{d}=\frac{1}{2} \varepsilon_{d}^{2}+\frac{1}{2} \varepsilon_{d}^{2}$

the time derivative is computed as:

$\dot{V}_{d}=\varepsilon_{d}\left\{-\frac{d i_{d}}{d t}-k_{d}^{\prime} i_{d}\right\}+\varepsilon_{d}^{\prime}\left\{-k_{d}^{\prime} i_{d}\right\}$.

Since $i_{d \text { ref }}=0$, then replacing $i_{d}=\varepsilon_{d}-\varepsilon_{d}^{\prime}$ in the above equation, we obtain

$\dot{V}_{d}=\varepsilon_{d}\left\{\frac{R_{s}}{L_{d}} i_{d}-p \frac{L_{q}}{L_{d}} \omega_{r} i_{q}-\frac{1}{L_{d}} v_{d}\right\}+k_{d}^{\prime}\left\{\varepsilon_{d}+\varepsilon_{d}^{\prime}\right\}\left\{\varepsilon_{d}-\varepsilon_{d}^{\prime}\right\}$.

Then, by choosing the control law $v_{d}$ as follows:

$v_{d}=L_{d}\left[k_{d}\left(i_{d r e f}-i_{d}+k_{d}^{\prime} \int_{0}^{t}\left(i_{q r e f} i_{q}\right) d t\right)+\frac{R_{s}}{L_{d}} i_{q}-p \frac{L_{q}}{L_{d}} i_{q} \omega_{r}\right]$,

and by substituting in Eq. (15), we obtain:

$\dot{V}_{d}=-\left\{k_{d}-k_{d}^{\prime}\right\} \varepsilon_{d}^{2}-k_{d}^{\prime} k_{d}^{\prime 2}$.

By choosing $\quad \bar{K}_{d}=\min \left\{\left\{k_{d}+k_{d}^{\prime}\right\} ; k_{d}^{\prime}\right\} \quad$ it $\quad \bar{V}_{d} \quad$ follows

$\dot{V}_{d} \leq-\bar{K}_{d} V_{d}$.

Then, this implies that under the control law $v_{d}$ the current $i_{d}$ tracks the desired reference:

$i_{d} \rightarrow i_{d r e f}=0$.

Finally, combining the action of the control inputs $v_{d}$ with $i_{d \text { ref }}$, the control objectives are achieved.

Proposition 1. We consider the system of the PMSM Eq (1), with references, $\omega_{r \text { ref }}$ and $i_{q \text { ref }}$, assume to be differentiable and bounded. Then, the trajectories of the closed loop system with orders tracking Eq. (10) and Eq. (16) following the exponentially references $\omega_{\text {r ref }}$ and $i_{d r e f}$.

\section{Control without speed sensor of PMSM integrated according to the MRAS}

MRAS (Model Reference Adaptive System) method is a technique belonging to the category of indirect speed estimation by exploiting tensions $\left(v_{d}, v_{q}\right)$ and the stator currents $\left(i_{d}, i_{q}\right)$ [10], [11]. It implements this technique using two independent models. The first is the reference model; it is used to determinate the two components of the stator current along the direct and quadrature axes (in the Park reference). Furthermore, the adaptive method for estimating the speed and the stator resistance are expressed by the second is the adjustable model. It is used to estimate the two components of the stator currents from the direct measurement of the stator voltages and currents. Canceling the discard between the stator currents of reference model and the adjustable model, we can estimate the rotor speed in dynamic mode. This discard is used by the adaptive mechanism to generate the estimated value and the converging towards the reference value.

\section{IV.1. MRAS Synthesis}

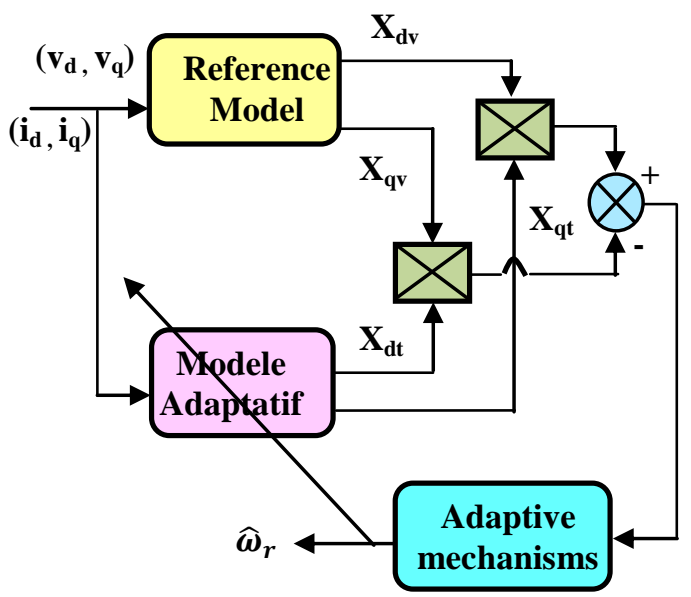

Fig. 1 Structure of MRAS for speed estimation. 
The first is the reference model; it is used to determinate the two components of the stator current along the direct and quadrature axes (in the Park reference). Furthermore, the adaptive method for estimating the speed and the stator resistance are expressed by the second is the adjustable model. It is used to estimate the two components of the stator currents from the direct measurement of the stator voltages and currents. Canceling the discard between the stator currents of reference model and the adjustable model, we can estimate the rotor speed in dynamic mode. This discard is used by the adaptive mechanism to generate the estimated value and the converging towards the reference value.

The adjustable model of this MRAS observer to salient pole $\left(l_{d} \neq l_{q}\right)$ is given by:

$\left\{\begin{array}{l}\frac{d \hat{\imath}_{d}}{d t}=\frac{v_{d}}{L_{d}}-\frac{\hat{R}_{s}}{L_{d}} \hat{\imath}_{d}+p \widehat{\omega}_{\mathrm{r}} \hat{\imath}_{q} \\ \frac{d \hat{\imath}_{q}}{d t}=\frac{v_{q}}{L_{q}}-\frac{\hat{R}_{s}}{L_{q}} \hat{\imath}_{q}-p \widehat{\omega}_{\mathrm{r}} \hat{\imath}_{q}-p \frac{\psi_{f}}{L_{q}} \widehat{\omega}_{r}+k_{e} \frac{\hat{R}_{s}}{L_{q}} \hat{\imath}_{q}\end{array}\right.$,

where $\widehat{\mathrm{R}}_{s}=-\frac{1}{p} \int_{0}^{t}\left(e_{d} \hat{\imath}_{d}+e_{q} \hat{\imath}_{q}\right) d t$.

with :

$$
\left\{\begin{array}{l}
e_{d}=i_{d}-\hat{\imath}_{d} \\
e_{q}=i_{q}-\hat{\imath}_{q}
\end{array}\right.
$$

Moreover, the adaptive method for estimating the speed and the stator resistance is expressed by:

$\widehat{\omega}_{r}=\frac{1}{p}\left(k_{p} e+k_{i} \int_{0}^{t} e d t\right)$,

with:

$e=i_{d} \hat{\imath}_{d}-i_{q} \hat{\imath}_{q}-\frac{k_{e}}{L_{d}} e_{q}$

where $k_{i}$ et $k_{p}$ are the gains of the corrector $P I, e_{d}$ and $e_{q}$ are errors in the stator currents.

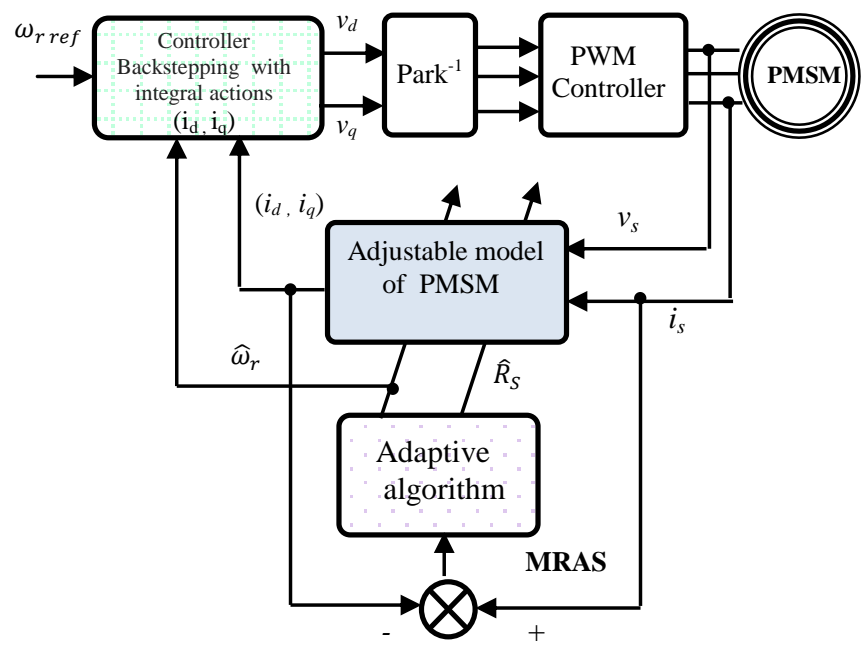

Fig. 2 Overall block diagram of the control.

The MRAS may be introduced into a control loop by Backstepping with integral action of PMSM, to observe its state variables. The diagram above shows a general structure of a MRAS related with a block control of PMSM by Backstepping with integral action.

\section{Simulation results}

To illustrate the mathematical analysis and, hence to investigate the performance of the proposed PMSM control of Backstepping with integral action according to the MRAS observer, simulations are carried out following the overall block diagram of the control shown in Fig. 2. Table 1 gives the nominal parameters of the PMSM which is used in the simulation tests. The simulation has been carried out using Matlab/ Simulink software. The machine started on the vacuum, then a load torque is applied of $5(\mathrm{~N} . \mathrm{m})$ at time $0.1 \mathrm{~s}$, and then eliminated at the moment has $0.2 \mathrm{~s}$. At time $\mathrm{t}=0.3 \mathrm{~s}$, the direction of rotation is reversed at $150(\mathrm{rad} / \mathrm{s})$ to -50 $(\mathrm{rad} / \mathrm{s})$. 
Table 1. The parameters of the PMSM.

\begin{tabular}{c||c||c||c||c||c||c||c}
\hline \hline$\omega_{\mathrm{r}}$ & $R_{S}$ & $L_{d}$ & $L_{q}$ & $\psi_{f}$ & $p$ & $j$ & $f$ \\
\hline \hline $157 \mathrm{rad} / \mathrm{s}$ & $0.6 \Omega$ & $1.4 \mathrm{mH}$ & $1.8 \mathrm{mH}$ & $0.12 \mathrm{~Wb}$ & 4 & $11 \times 10^{-4} \mathrm{~kg} \cdot \mathrm{m}^{2}$ & $14 \times 10^{-4} \mathrm{~N} \cdot \mathrm{ms} / \mathrm{rad}$ \\
\hline \hline
\end{tabular}

Gains control used in this paper are: $k_{\Omega}=0.01, k_{\Omega}^{\prime}=139, k_{q}=2900, k_{q}^{\prime}=150, k_{d}=100$, and $k_{d}^{\prime}=900$. In these results the actual motor speed was calculated from the end position by the encoder.

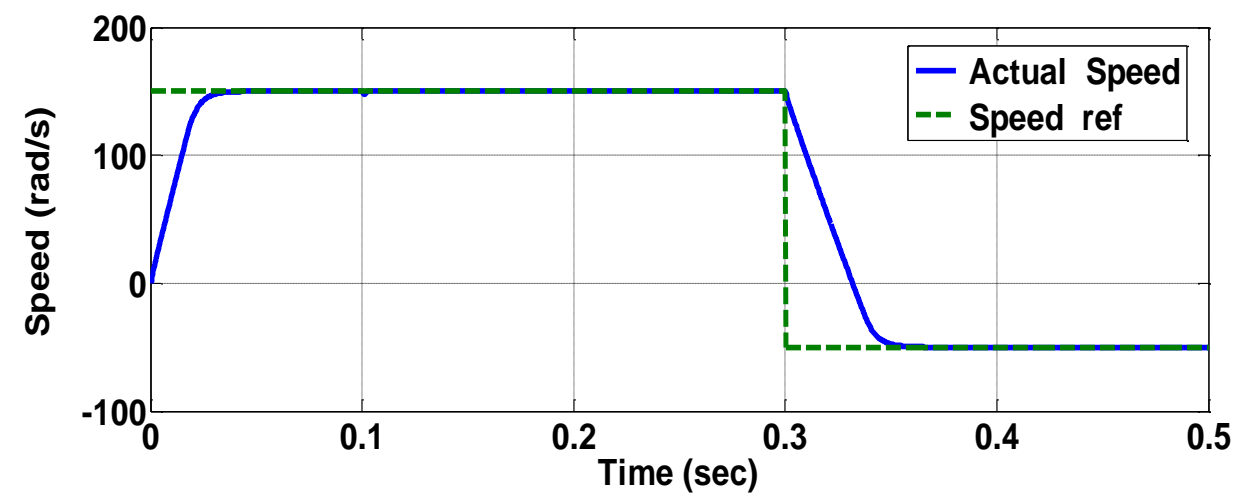

Fig. 3 Speed rotation $[\mathrm{rad} / \mathrm{sec}]$.

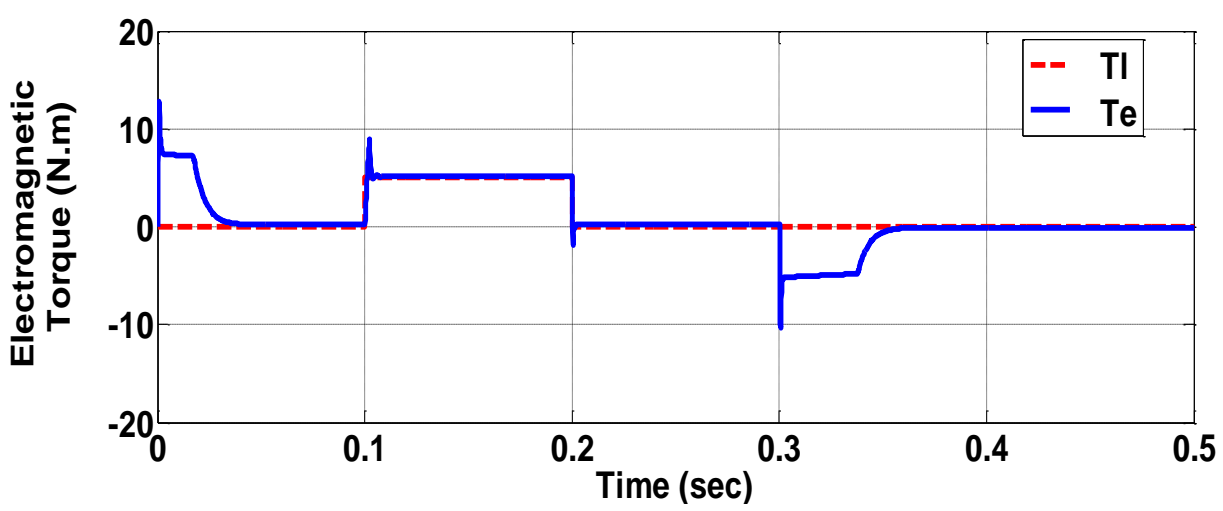

Fig. 4 Electromagnetic torque [N.m].

Figures 3 and 4 are noted that according to shape of the speed perfectly follows its reference which is achieved very rapidly, with a very fast response. The effect of the perturbation is rapidly and the electromagnetic torque stabilizes the load torque value.

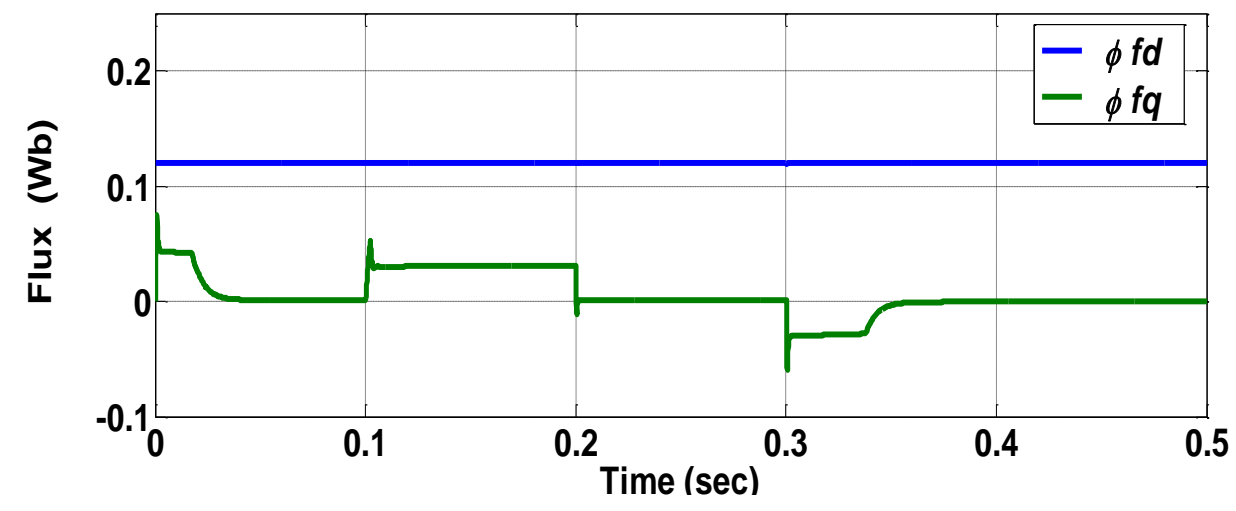

Fig. 5 Flux $[\mathrm{Wb}]$. 


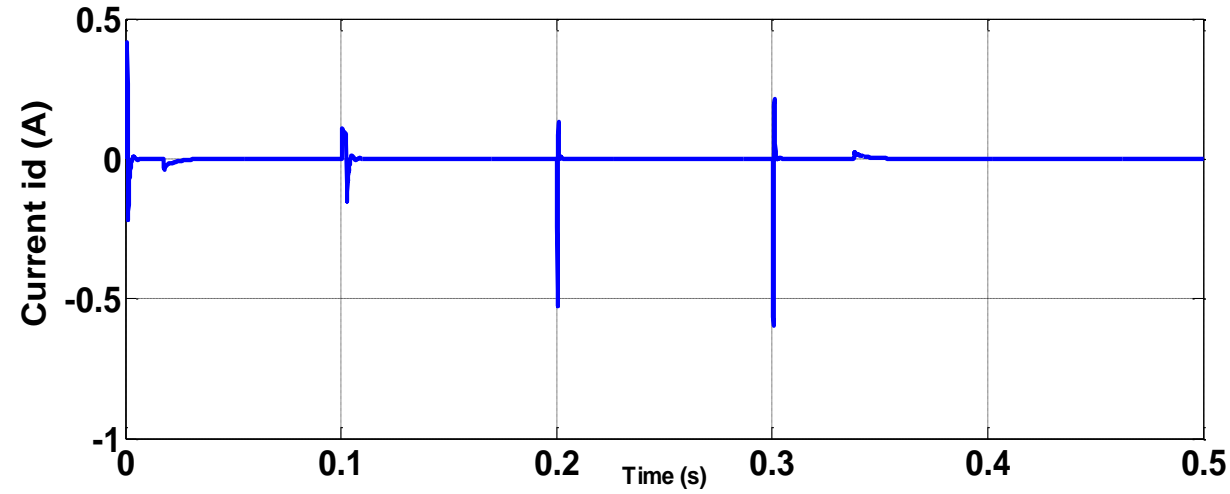

Fig. 6 Current $i_{q}[\mathrm{~A}]$.

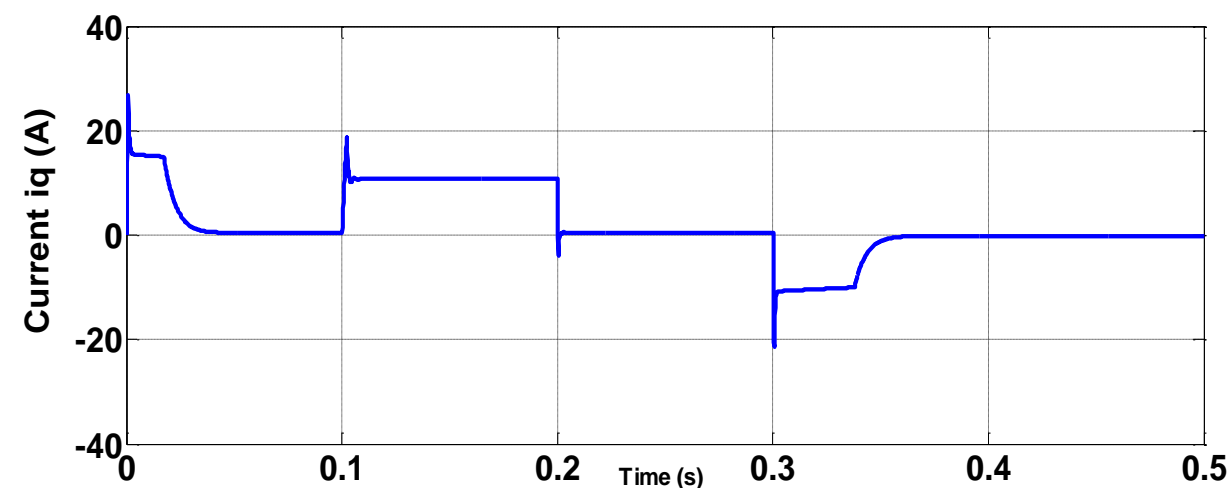

Fig. 7 Current $i_{d}[\mathrm{~A}]$.

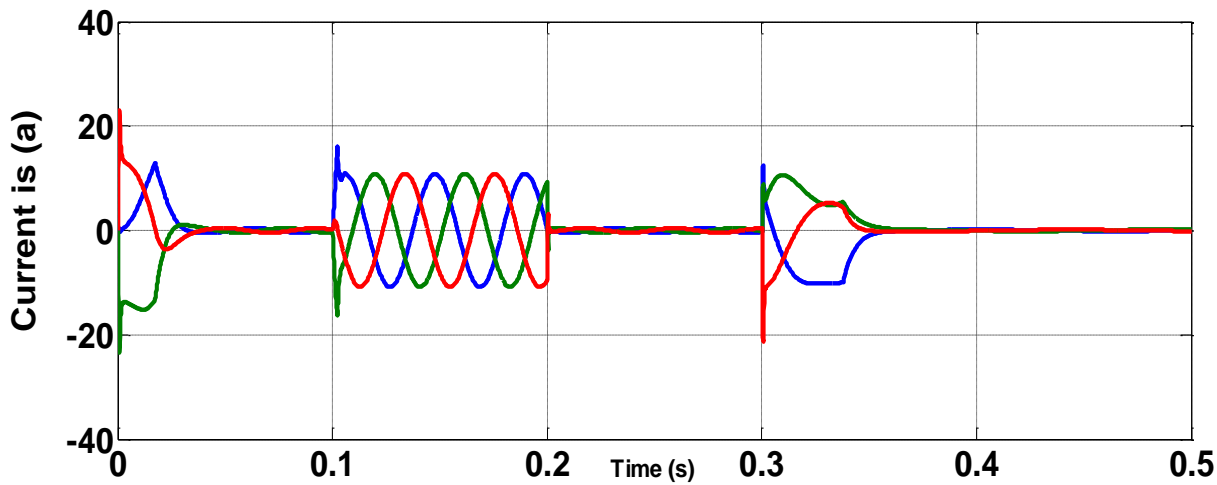

Fig. 8 Stator current $[\mathrm{A}]$.

Figures 5 to 7 illustrate the response of the two current components $i_{d}$ and $i_{q}$ show good decoupling introduced by PMSM control (the current $i_{d}=0$ ). The current $i_{q}$ is the couple image, and the phase sinusoidal shape of the current with a peak at start-up. 


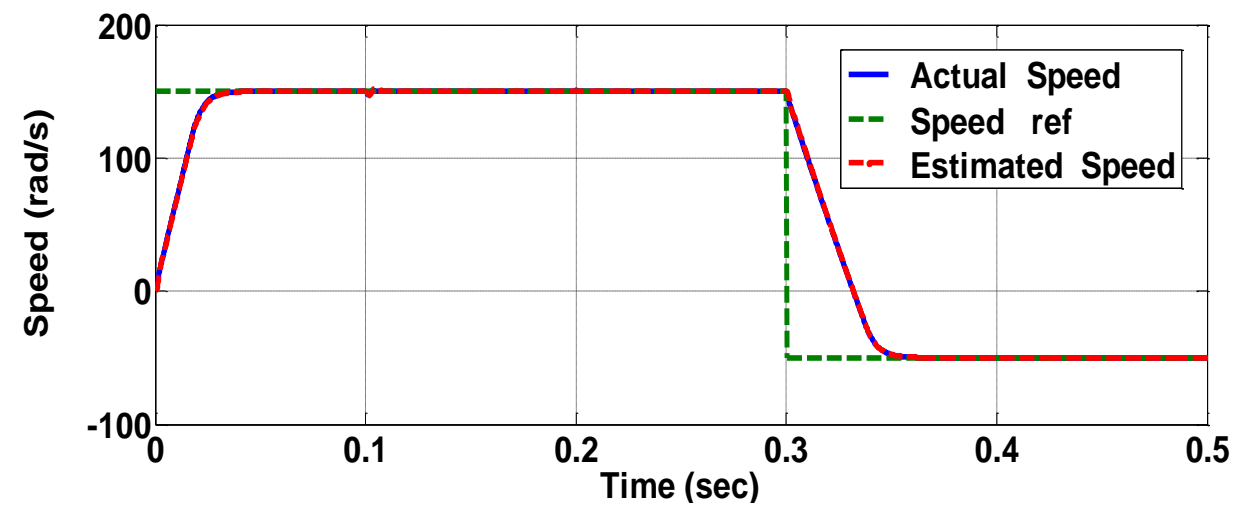

Fig. 9 Speed of rotation $[\mathrm{rad} / \mathrm{sec}]$.

Figures 9 to 11 illustrate the dynamics behaviors of PMSM according MRAS observer at a servo-control of speed at the vacuum and a load torque is applied at $5(\mathrm{~N} . \mathrm{m})$ at time $0.1 \mathrm{~s}$ and eliminated at $0,2 \mathrm{~s}$. At time $\mathrm{t}=0.3$ the direction of rotation is reversed at $150(\mathrm{rad} / \mathrm{s})$ to $-50(\mathrm{rad} / \mathrm{s})$, this time the values of the speed used in the feedback loop are estimated values.

These results are obtained with the same conditions as those obtained without MRAS observer (Fig. 3).

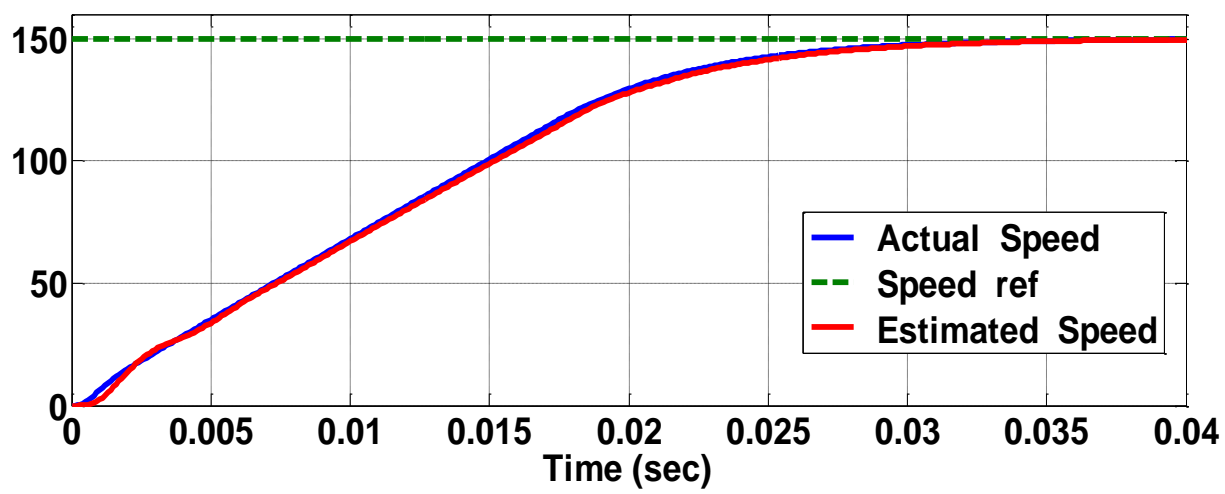

Fig.10 Zoom speed of rotation $[\mathrm{rad} / \mathrm{sec}]$.

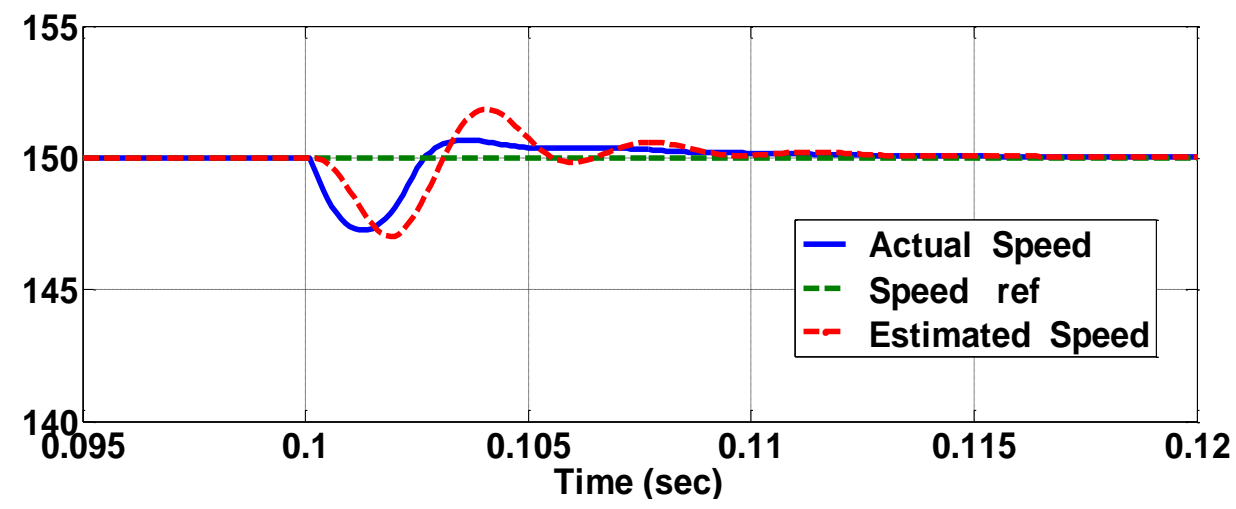

Fig. 11 Zoom speed of rotation $[\mathrm{rad} / \mathrm{sec}]$.

Moreover, figures 10 and 11 show a zoom speed evolution in which the notes set is perfectly superimposed on the estimated speed. 


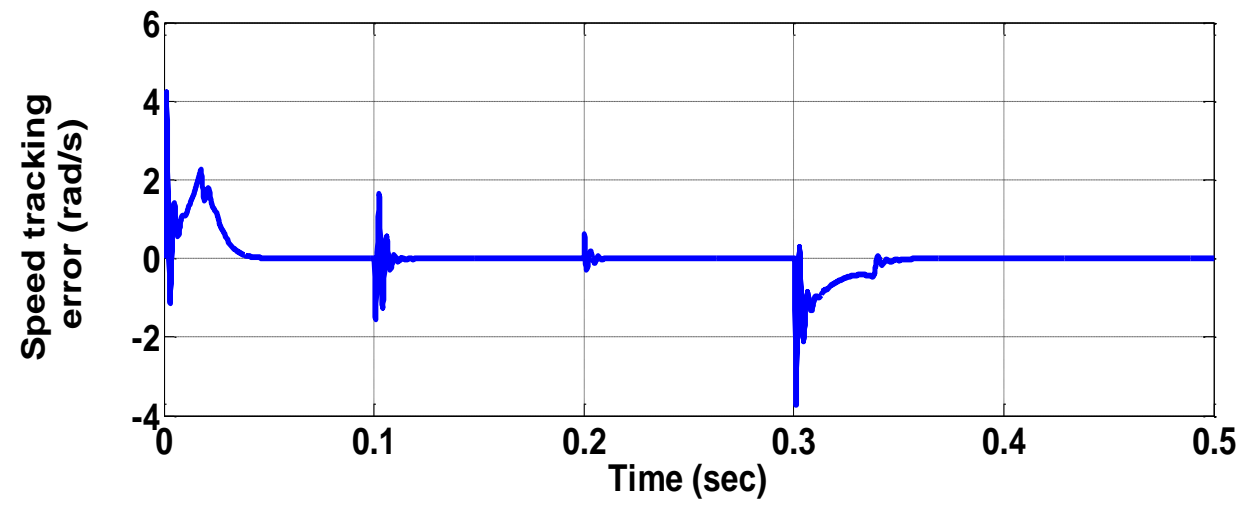

Fig. 12 Speed tracking error $[\mathrm{rad} / \mathrm{sec}]$.

Figure 12 shows the speed tracking error. The speed estimation error, it is also shown that this estimated speed follows the actual speed with precision on permanent regime. Against by the transitional regime (starting and reversing the direction of rotation), this error is acceptable and does not affect the static and dynamic behavior of the control and also the overall drive system.

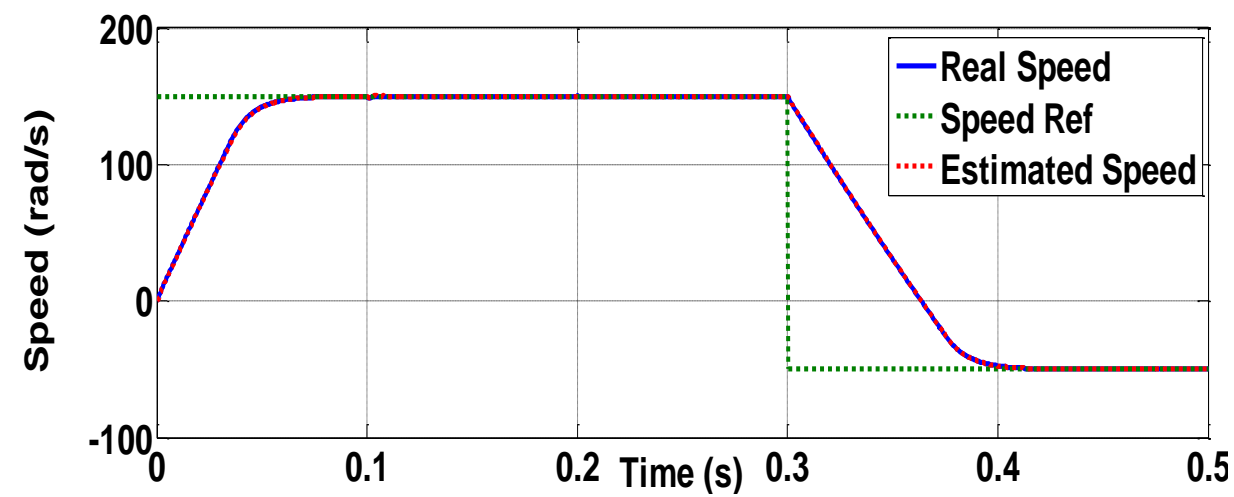

Fig. 13 Simulation results during the variation of inertia $j$.

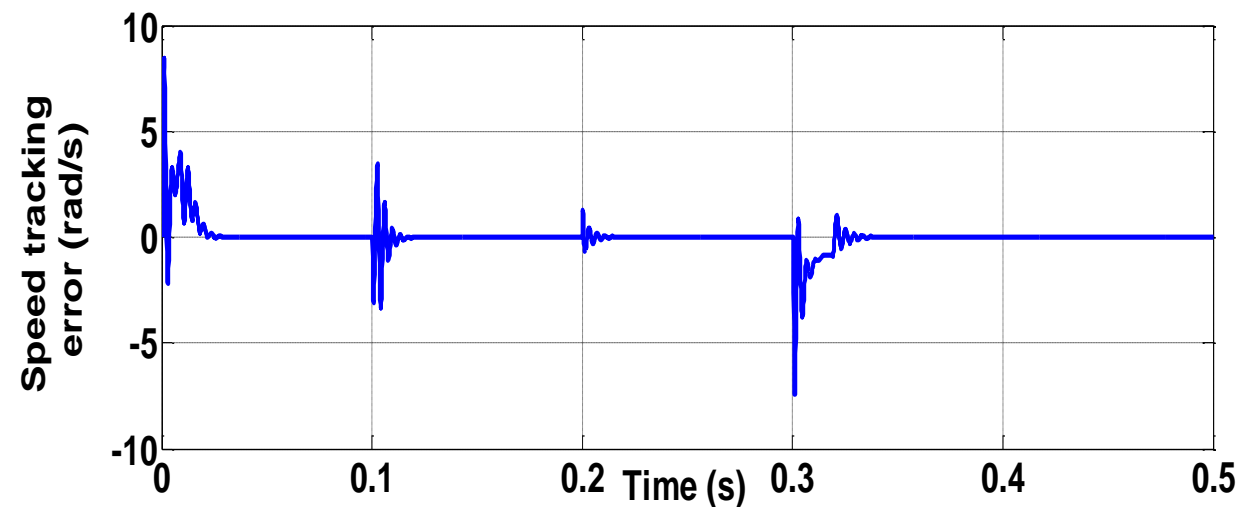

Fig. 14 Speed tracking error $[\mathrm{rad} / \mathrm{sec}]$.

Figures 13 and 14 show error of $+100 \%$ on the nominal value the moment of inertia does not affect the static and dynamic performance of the Backstepping control and the MRAS observer.

Finally, we present the results obtained from actual simulation runs that, the MRAS observer is successfully established for a nonlinear robust sensorless towards the load change. 


\section{Conclusion}

This paper based on Backstepping control with an integral action for PM synchronous motor integrated according to the MRAS observer, which is addressed in a hand, as a tool for a new nonlinear control speed PMSM, and in the other hand as a tool for studying dynamic stability.

However, the simulation results exhibited a significant improvement in performance. This improvement manifests itself at the speed of signal quality, and the level of almost total rejection of the perturbation (charge couple). Moreover, to overcome the problem of control without mechanical sensors, we used a method based on MRAS technique, for estimating speed from the measured voltages and currents. The speed elimination sensor reduces the constraints and gives more flexibility to control the machine. In the light of the simulation results, we can conclude that the objective of this study is achieved. Thus, the Backstepping technique to the integral action combined with vector control offers high control performance. The intrinsic robustness Backstepping is strengthened through full terms added to it.

\section{References}

[1] B. Belabbes, M.K. Fellah, A. Lousdad, A. Meroufel, A. Massoum, Speed Control by Backstepping with Nonlinear Observer of A Permanent Magnet Synchronous Motor, Acta Electrotechnica et Informatica, 6( 4), 2006.

[2] M. Oussaid and M. Maaroufi, Improved nonlinear velocity tracking control for synchronous motor drive using backstepping design strategy. In IEEE Power Tech Conf, St. Petersburg, Russia 2005

[3] Hai Lin, Weisheng Yan, Yintao Wang, Bo Gao and Yao Yao, Nonlinear Sliding Mode Speed Control of a PM Synchronous Motor Drive Using Model Reference Adaptive Backstepping Approach, Proceedings of the IEEE International Conference on Mechatronics and Automation August 9- 12, Changchun, China, 2009.

[4] A. Kechich and B. Mazari, Application to Adaptive Backstepping for a Permanent Magnet Synchronous Machine, ACTA ELECTROTEHNICA Vol. 53(1), 2012.

[5] Yang Yun, PMSM Stabilizer Design Based on Backstepping, International Conference on Power, Energy and Control (ICPEC), 2013.

[6] M. Azizur Rahman, D. mahinda Vilathgamuwa , M. Nasir Uddin, and King-Jet tseng, Nonlinear Control of Interior PermanentMagnet Synchronous Motor, IEEE Transactions On Industry Applications, 39(2), March/April 2003.

[7] M. Karabacak and H. I. Eskikurt, Speed and current regulation of A Permanent Magnet Synchronous Motor via Nonlinear and Adaptive Backstepping Control, Mathematical and Computer Modelling 53, 2015-2030, 2011.

[8] F. Zouari, K. Ben Saad and M. Benrejeb ,Robust Adaptive Control for a Class of Nonlinear Systems Using the Backstepping Method, International Journal of Advanced Robotic Systems, 10, 2013, 166.

[9] M. A.Hamida, A. Umineau, and J.D. Leon ,Robust Integral Backstepping Control for Sensorless IPM Synchronous Motor Controller, Journal of the Franklin Institute 349, 2012, 1734-1757.

[10] A. Akrad, M. Hilaire, and D. Diallo, Design of a Fault-Tolerant Controller Based on Observers for a PMSM Drive, IEEE Transactions On Industrial Electronics. 58( 4), April 2011.

[11] M. Comanescu, and L. Xu, Sliding-Mode MRAS Speed Estimators for Sensorless Vector Control of Induction Machine, IEEE Transactions On Industrial Electronics, 53(1), Feb 2006. 